\title{
Sensitivity in Residential Design Towards Sustainability - A Vernacular Approach
}

Ar. Vanishree Mysore Ranganath

Assistant Professor, Faculty of Architecture, PES University, Bengaluru

Email: vanishreemr@pes.edu

\section{ARTICLE INFORMATION}

Received: September 11, 2018

Revised: November 1, 2018

Accepted: December 7, 2018

Published online: January 8, 2019

\section{Keywords:}

Reflexive relationship, Sustainable development, Residential planning, Design sensitivity, Pragmatic approach, Vernacular concepts

\section{ABSTRACT}

Vernacular design depicts a visual imagery of myriad layers of environmental, socio-cultural and economical ways of life. Initially, the development of Vernacular concepts originated with articulation of spaces to accommodate different forms of shelter appropriate to micro and macro climatic conditions across varied geographical locations.

Later, it established an affinity for the place where the landscapes embraced these indigenous resources and practices and ensured compatibility between people, nature and human built environment. Hence, a reflexive relationship between nature and built environment which includes the necessity to create and adopt the right methodology evolved with time.

Further, this pragmatic approach not only stands as an evidence to prove the positive impact it has on the environment but also holds the key to a sustainable development. An insight into diverse residential development patterns across different geographical locations in Indian subcontinent substantiates the above statement. The parameters that dictate the built form of these dwellings also contribute to the degree of design sensitivity towards the sustenance of that built form. This paper specifically analyses the factors that define the scope of residential planning across Peninsular India, North - Western regions and North -Eastern parts of India. This paper will also investigate the resilient nature of these factors which play a predominant role in the providing a conducive environment for sustainable development.

\section{Introduction}

The meaning of a built environment is more than just four walls and a roof. It encompasses and addresses different aspects of human life such as - shelter - a physical need, expression of identity \& solidarity, cultural continuity, community living, security and the narrates / celebrates the spirit of time. All forms of Vernacular architecture stand as a testimony of time which analyse the link between built forms and its reflexive relation with its surrounding. The design reflects the architectural grammar involved in the creation of residential spaces and acts as a unifying element which creates a cultural pattern that revolves around life, culture and architecture. Vernacular design practices play a deterministic role in Indian architecture, because of its power to manifest and remain resilient, despite the regional and temporal variations. The famous world renowned modern architect Le Corbusier said, "The home should be the treasure chest of living". It is a small world in itself. The various factors that affect and define the scope of residential planning in a Vernacular context are:

Climate - the features of the environment that surround a specific geographical location

\section{Naturally available local materials}

Culture and traditions - that are inherited by the society or the community and passed on to the future generations. Now let us discuss how these factors have assisted the design of various vernacular dwellings.

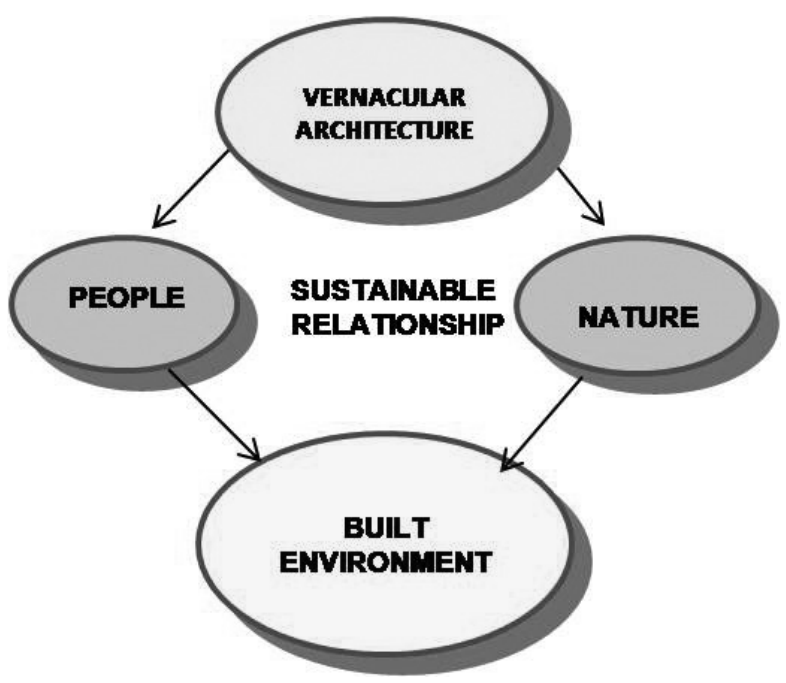

Figure 1. Sustainable Relationship (Source: Author) 


\subsection{Factors that Contribute for the Design of Vernacular Dwellings}

Climate: This is the most important factor that dictates and determines the architecture of the built form is Climate. The climate of a country plays a major role in its economy, shaping the socio-cultural lives of the people, type of vegetation that grows, wildlife . Famous Indian architect Charles Correa said "Form follows climate". The built environment constantly interacts with the microclimate in that geographical arena. This has a direct impact on the comfort conditions of the inhabitants as well as their social lives in and around that built environment. Rainfall, wind speed \& direction, relative humidity levels, snow, light $\&$ intensity of radiation are some of the climatic factors which have profound impact on the built environment. Climate is the primary instigator influencing the development of traditional construction practices that has evolved with time and created the architectural typology of built forms which have proven to be sustainable. There are broadly six climatic zones in India - Hot \& Dry Zone, Warm Humid Zone, Cold \& Sunny, Composite Climate, Cold \& Cloudy, Moderate Zones. All elements of design such as roofs, slabs, walls, fenestration, are all perceived in response to the prevailing climatic conditions.

\section{Broad Classification of Climatic Zones in India and their Characteristic Influence on Planning}

\subsection{Warm-Humid climate}

Let us look at the typo morphology of roofs with deep overhangs in Warm -Humid climate type prevailing in some of the regions in inland peninsular India like Kerala, coastal Karnataka, Andhra \& Tamil Nadu. This type of climate is characterized by high precipitation throughout the year around on an average of $3000 \mathrm{~mm}$ with relative humidity levels which is more than $70 \%$ on an average annually and sandy soil because of longer coastline. All these factors support the growth of thick vegetation and tall palm trees like coconuts and arecanuts.

\subsubsection{Roof}

The most important element that envelopes the volume of the built space and establishes the relationship between the whole to the part is the roof. It also acts as regulating element. The evident roof form is the sloping roof with deep overhangs. This form may have been inspired or evolved from the overhanging and triangular profile of a coconut leaf (Fig ii). The geometry of the leaf naturally drains off the rainwater. The swaying of tall trees facilitate the hot air circulation that raises up from the ground and helps in its movement which keeps the environment cooler and breezy. The same concept is applied to ensure the comfortable ambient atmosphere throughout day and night in the interiors.

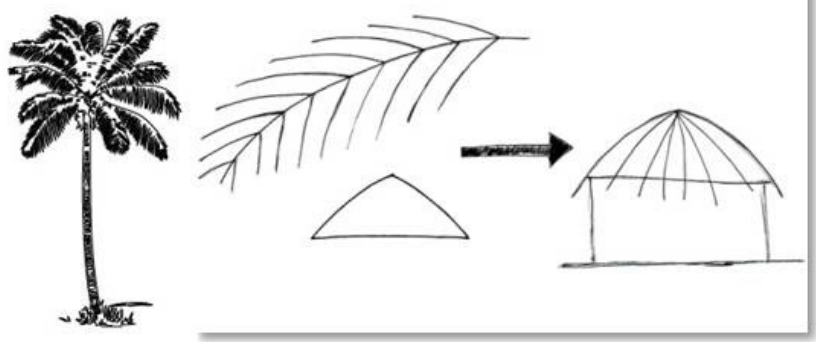

Figure 2. Evolution Of Form (Source: Author)

\subsubsection{Planning}

The most common geometric building profile of buildings here is the rectilinear form. The prime idea of design is to articulate and channelize the movement of air and ensure cross ventilation to maintain comfort conditions in the interiors. The evolution of form is achieved by puncturing a cuboid to create a centralized open courtyard space and that volume of space is added to the front of the same cuboid to create a verandah or porch - a public space, which acts as a buffer that has a wind tunnel effect to channelize the air movement (Fig 3). It also generates the hierarchical sequence of spatial layers ranging from open to semi open to closed areas.

The courtyard, an internal open space, is another integral element in all scales of domestic architecture. They act as organizational space serving various levels of privacy. The courtyard plays a significant role in regulating the air movements from exterior to the interior and admitting light and ventilation by enhancing the spatial quality (Fig 4).

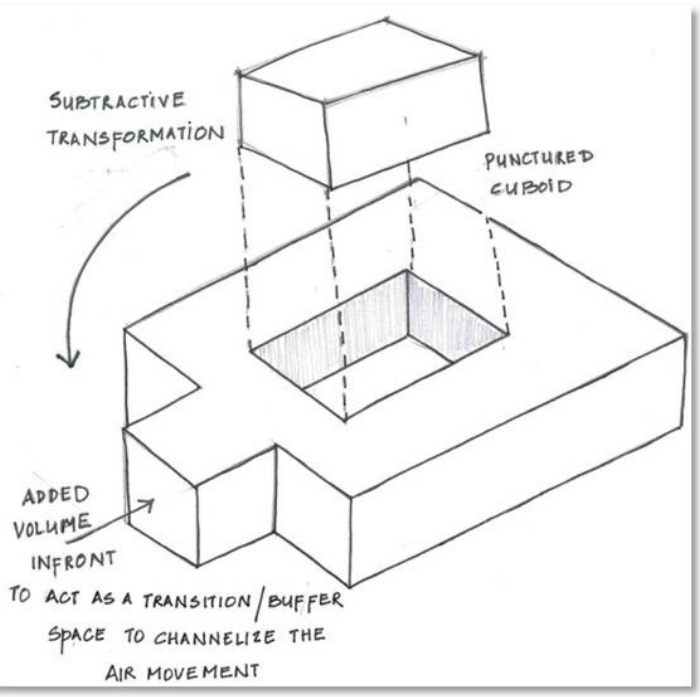

Figure 3. Manifestation of Form (Source: Author) 
As the tradition says, the courtyard type of house is called Haveli in North India, Wada in Maharashtra, Rajbari in West Bengal, Deori in Hyderabad, Chathurmukham in Tamil Nadu, and Nalukettu in Kerala.

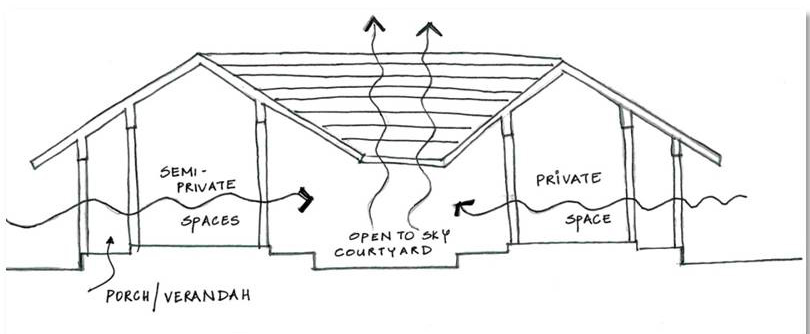

Figure 4. Courtyard Effect (Source: Author)

The articulation of this spatial volume is defined by the enclosing elements, and it is dependent on the size of building and its users. The courtyard is generally centralized so that all the areas like private, semiprivate areas of a dwelling are arranged around so as to accommodate dissipation of hot air about the four corners of a quadrangle more efficiently and thereby reducing the time taken for retention of relative humidity levels in the interiors. The movement of hot air would have been circumambulatory had the form of the dwelling been circular or curvilinear which hampers the efficiency of heat exchange from exterior to interior and increases the relative humidity levels in the indoors. The walls are generally made of Bricks, Stone masonry with roof joists and columns made of timber and concrete. The openings are larger in size and to reduce the intensity of solar radiation, the openings in the upper floors are louvered or grilled to further strengthen the continuous movement of air.

\subsection{Cold and Cloudy Climate}

Let us move towards the diverse Northern and North - Eastern parts of India and look at some of the vernacular dwelling types in Himachal Pradesh, Shimla, Arunachal Pradesh, Assam, Nagaland, Mizoram. Most of these parts fall in to a diversified hilly tropical monsoon zones which is characterized by cold and cloudy climatic conditions. This type of climate is characterized by prolonged winters and short summers. They receive fair amount of precipitation spread across the year. These areas are constantly susceptible to natural calamities like landslides, floods. The design criteria is to increase thermal resistance by the use of materials and finishes, increase the thermal capacity by retention of heat, roof insulation and thermal massing to reduce the surface exposure (Fig 5).

\subsubsection{Roof}

The roof is a typo evolution from the surrounding coniferous trees to ward off heavy rainfall. These trees grow taller to receive ample amount of sunlight also uniformly and they are very compact. Similarly the type of roof commonly seen in these areas is the sloping roof with an attic or just a steeply pitched gabled or hipped roof. The attic is generally provided with an opening to receive direct sunlight at an elevated plane from the ground level and smaller openings at the lower level which normally receive dissipated sunlight. The spatial development of dwellings is seen vertically while it is very compact horizontally, this is to minimize the surface exposure. The built forms that have evolved on the hill slopes are oriented in such a way that they receive optimum intensity of light and solar radiation. Further analysis reveals the spatial volumes are so demarcated that lower portion of the dwelling is predominantly used for cattle and dry storage. Then the structure raises above this space and accommodates habitable spaces like living rooms with larger openings. The kitchen is integrated with living areas, so that the habitable spaces remain warmer through the heat generated by cooking. The pitch of the timber ceiling is deliberately lowered so that heat dissipation is uniform and retained for longer periods. Window openings are oriented in direction of Sun rays generally the North \& the Eastern sides.

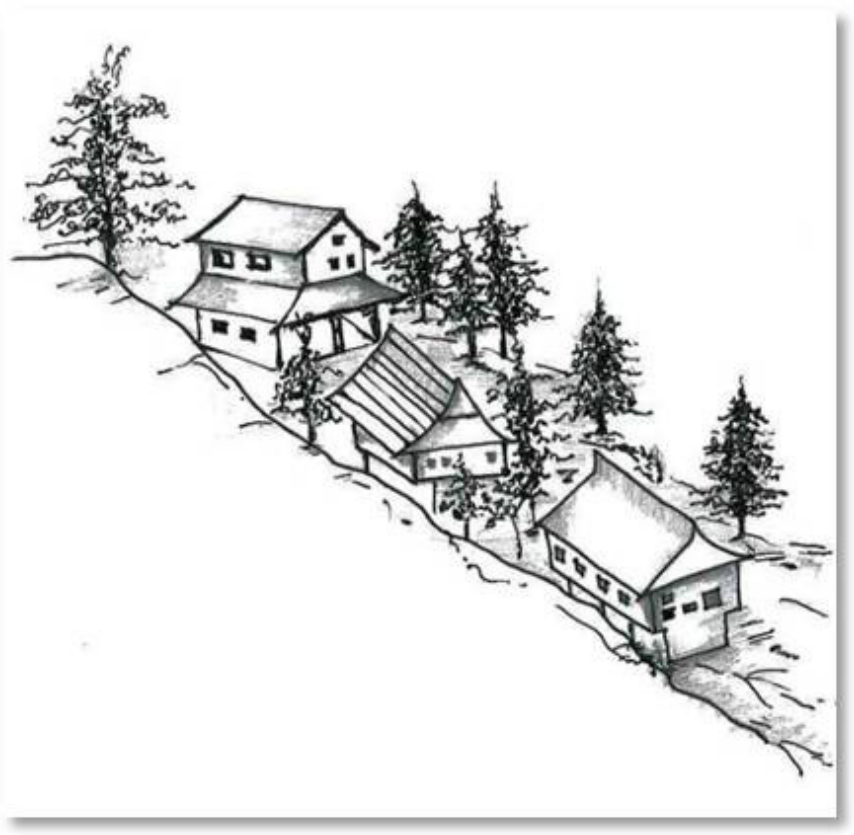

Figure 5. Dwellings On Undulating Topography (Source: Author)

The roof members are generally wooden joists supported by rafters, beams and purlins, and struts that strengthen diagonally to secure the structural stability and integrity of the roof. The floor slab is also constructed similarly using wooden members. This type of construction develops lower shear stresses and bending strength of dry stone walls. This type of 
dry wall construction has evolved from the traditional Khath-Khuni construction of Himachal Pradesh in which involves the construction technique with wooden members laid horizontally between infill materials generally stone, shingles etc. Due to unavailability of timber these days, an alternative sustainable technique is developed using cement-sand mortar sandwich panels laid in horizontal layers and reinforced galvanized steel wire mesh with provision for expansion joints.In eastern parts of India like Assam, Meghalaya, Tripura, and the rest of the North East, the use of bamboo has been an integral part of the cultural, social, economic traditions of these regions. A mature, cured bamboo of the right species can last a lifetime. Bamboo is used extensively for walls, roof trusses and floors in traditional construction methods. This is because bamboo is available in abundance and also easy to use.

\subsubsection{Planing}

Another important feature in these areas, the articulation of form is square or a rectangle. Some of the hilly areas at an altitude exhibit cold and cloudy climate. When the contour of the building is rectangular, it is more suitable because of the equal and uniform distribution of the surface of the built area. The structure is essentially raised on a common platform from a sloping ground in order to achieve a leveled horizontal base plane. If the internal volumes of the built form is not unified under an single overhead plane, volume of the interior to surface ratio will result in increase in the heat loss from surfaces. Hence the height of the rooms is kept low to keep the interiors warm. (Fig 6).

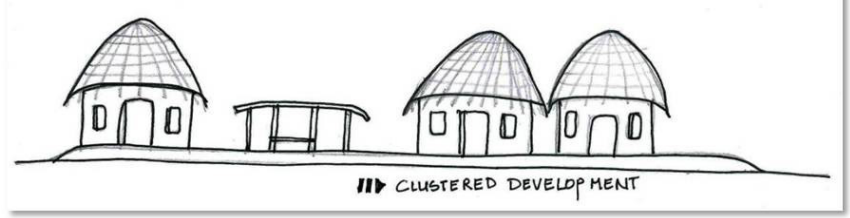

Figure 6. Clustered Communities (Source: Author)

\subsection{Hot \& Dry Climate}

With the context and setting in the Western parts of the Indian sub continent, like Gujarat and Rajasthan, where Mud wall plaster and thatch roof construction is a predominant pattern. The degree of resilience of this structure between the sand dunes of Thar and the salt plains of Kutch is very high. The Bhonga structure in the regions of Kutch re very indigenous earthquake resistant structures.

\subsubsection{Roof}

The regions of Kutch are prone to frequent earthquakes. A Bhonga is a traditional dwelling which is circular in plan, with conical roof, supported by cylindrical walls. The circular walls are made of mesh of mud plaster, which consist of Mud cobs that are laid one above the other and reinforced with reeds or split twig sections and then plastered with mud.

\subsubsection{Planning}

Due to the circular shape of walls and the vertical support of the wooden posts, the internal forces developed in the inner volume of the structure are resists the lateral external forces. The thick mud walls are good thermal insulators and have high in plane stability that can withstand and resist the lateral forces. (Fig 7). Also Bhongas are independent structures, not attached to each other (Fig 6). But all unified on a single platform or plinth. It is a clustered development. The Dhajji frame construction techniques in timber, in the northern parts of India like Kashmir is also another indigenous solution to earthquake resistance. The large scale sustainable residential developments in urbanscape of Rajasthan like in cities of Jaisalmer, Jaipur, Udaipur, a number of typo morphology of dwelling patterns which exhibit effective responsiveness to the prevailing hot dry desert climate. Some of the unique architectural features like the courtyard, pavilions, sun shades \& screens, terraces, texturing of surfaces using available local materials and craftsmanship, orchestrates a unique spatial narrative as shown in $\operatorname{Fig}(8)$.

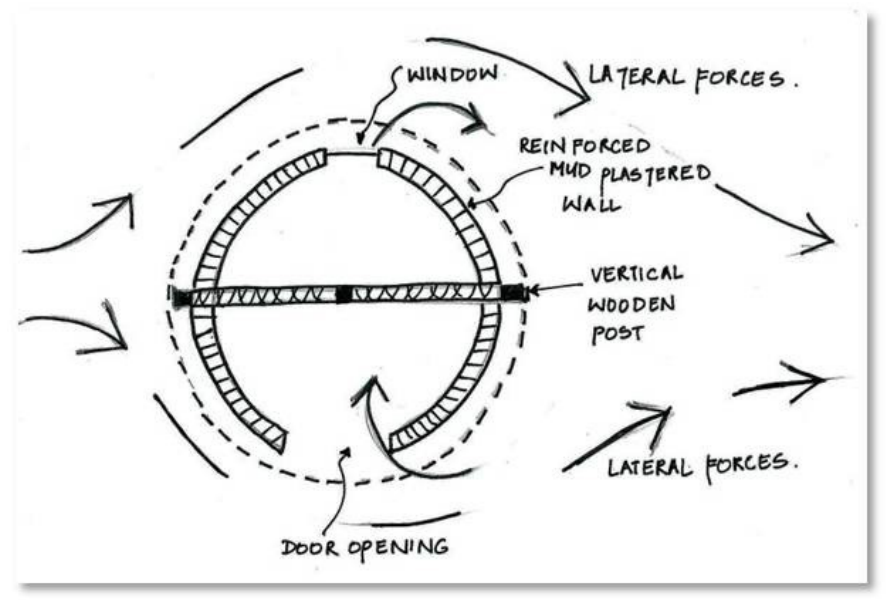

Figure 7. Lateral Forces On Circular Structures (Source: Author) 


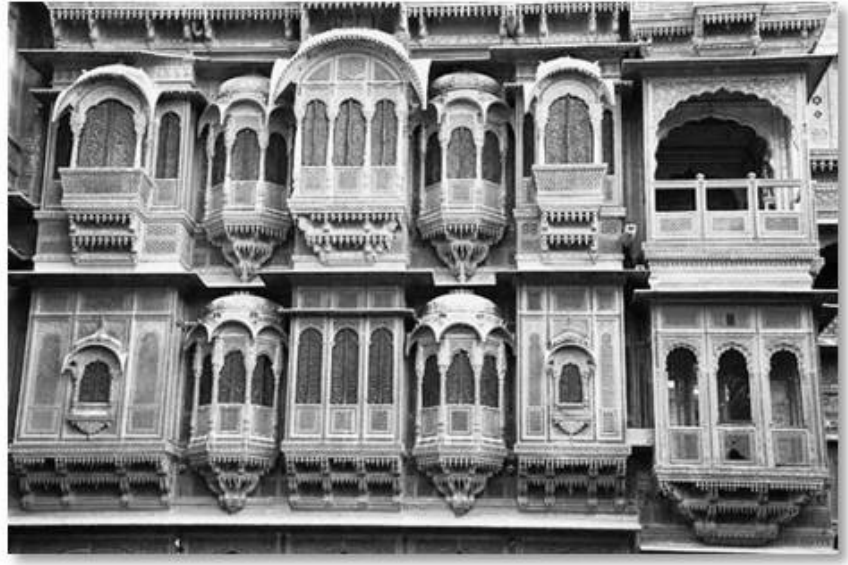

Figure 8. Surface Articulation By Ornamenatation (Source: HYPERLINK "http://www.flickr.com" Www.Flickr.Com (Images That Are Free To Modify, Share And Use Commercially))

\section{Naturally Available Construction Materials}

As the famous Indian architect, B. V Doshi said, “ Design is nothing but a humble understanding of materials, a natural instinct for solutions and respect for nature". The locally available natural materials are the prime construction materials that have withstood the testimony of time.These natural materials are highly subjected to regional variations. Some of the common type of materials which are available are listed below:

Geographical location Traditional Construction Materials

Peninsular India

Baliapatam Tiles, Timber, Clay, Palm leaves, Shingles, Terracotta tiles, Aathangudi Tiles, Mangalore Tiles, Adobe, Sadarhalli Stone, Timber - Coconut barks, Arecanut barks, Mud Bricks, Cowdung, Rammed Earth, Thatch, Kota Stone, Cuddapah stone, Compressed Earth Blocks, Clay bricks

Western India - Bricks, Mud, Adobe, thatch, Jaisalmer Marble, Sandstone, Limestone, Slate

Northern regions - Stone, Clay, Shale, Timber, Slate tiles, Shingles

Eastern Regions - Bamboo, Ikra reeds, Cane, Straw, Timber, Mud, River stone

\section{Culture and Traditions}

Culture has a profound impact on the development of a specific style of architecture pertaining to that geographical location. The life style of the people, the socio - economic status has profound impact on built forms. The size of family, pattern of space usage, the religious beliefs \& practices, the occupation of people, the interactive social groups the family associates itself with, determines the scale, size and style of residences.

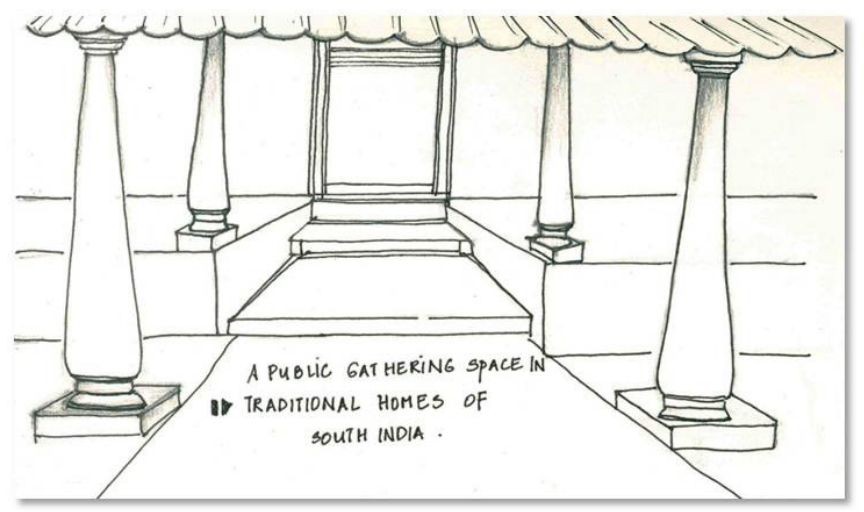

Figure 9. Interactive Spaces (Source: Author)

Consider the Bhonga dwellings in Kutch region where a community living pattern exists, hence it is a clustered development of small communities. Down South, there is a small gathering space in the front of the house which is referred to as thinnai in Tamil Nadu, mukhamantapa in Kerala, balcao in Goa, jagalikatte in Kannada, the raised platform on stilts in the eastern regions of Assam, Meghalaya, the community interaction, family gathering space, which is an integral part of Indian culture.

In rapidly developing Indian urban scenario, where the energy consumption is all time high, the need for a sustainable and an inclusive design approach is absolutely essential. Vernacular design concepts manifest themselves time and again. A holistic design intervention is required where it can be adopted, modified and applied to provide feasible design solutions.

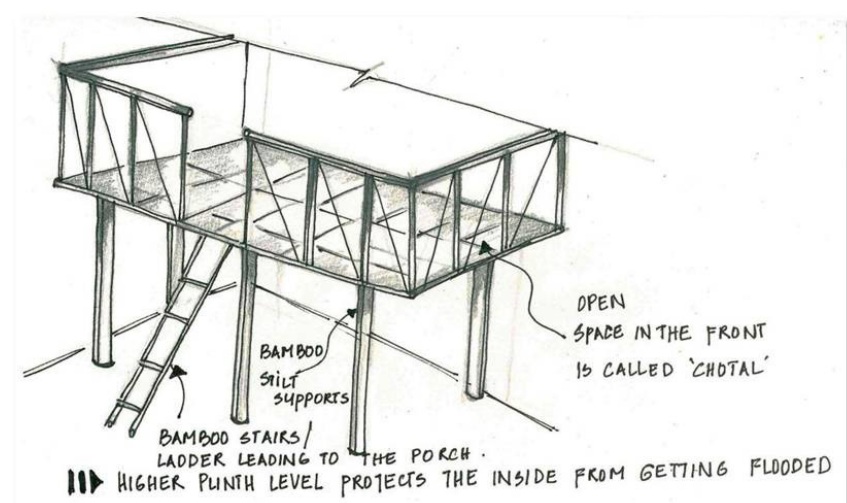

Figure 10. Raised Plinths (Source: Author) 


\section{References}

Bhonga Vernacular Architecture of Gujarat -www.slideshare. net

Courtyards: Influence of the Indian Traditional Architectural Element on Community interactions - www.gounesco. com

Frontiers of Architectural Research -ScienceDirect.com

Prathaa - Kath -Khuni Architecture of Himachal Pradesh by Bharat Dave, Jay Thakkar, Mansi Shah
The Vernacular Architecture of Rajasthan/Courtyard/ Climate - www.scribd.com

Traditional \& Vernacular Architecture by Jyoti Mehra www.academia.com

Tribal Houses of North East India - Art \& Culture - www. nelive.com

Vernacular Architecture of Jaisalmer - www.slideshare.net 